\title{
Introduction to the EFSNE project collection of papers
}

Christian J. Peters ${ }^{\text {a } *}$
Tufts University

Tufts University

Kate Clancy ${ }^{\mathrm{b}}$

Food Systems Consultant

C. Clare Hinrichs ${ }^{c}$ and Stephan Goetz ${ }^{\mathrm{d}}$

Pennsylvania State University

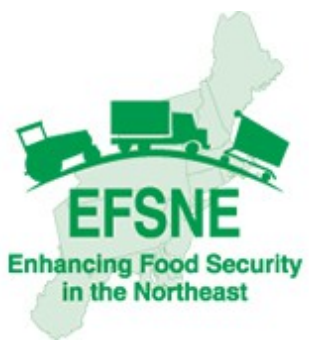

in the Northeast

Submitted April 10, 2017 / Accepted April 11, 2017 / Published online December 20, 2017

Citation: Peters, C. J., Clancy, K., Hinrichs, C. C., \& Goetz, S. (2017). Introduction to the

EFSNE project collection of papers. Journal of Agriculture, Food Systems, and Community

Development, 7(4), 159-162. http://dx.doi.org/10.5304/jafscd.2017.074.019

Copyright (C) 2017 by New Leaf Associates, Inc.

\section{Abstract}

The Enhancing Food Security in the Northeast (EFSNE) project started in 2011 to explore the potential for regional food systems to improve food security in the Northeastern U.S. Building on the nationwide interest in local food systems, EFSNE researchers have been motivated by a desire to understand whether regional food

a * Corresponding author: Christian J. Peters, Friedman School of Nutrition Science and Policy, Tufts University; 150 Harrison Avenue; Boston MA 02111 USA; Christian.Peters@tufts.edu

b Food systems consultant; University Park, MD 20782 USA; klclancy@,comcast.net

c Professor, Department of Agricultural Economics, Sociology \& Education, The Pennsylvania State University; 111D Armsby Building; University Park, PA 16802 USA; chinrichs@psu.edu

d Stephan Goetz, Professor of Agricultural and Regional Economics, The Pennsylvania State University; 7-E Armsby Blvd.; University Park, PA 16805 USA; sgoetz@psu.edu systems, which have a larger geographic scope, might have some of the perceived sustainability benefits attributed to local food while providing food accessible to all consumers. To this end, an interdisciplinary team drawn from academic institutions, federal government research organizations, and nonprofits has spent seven years trying to understand food consumption, distribution, processing, and production in the Northeast. Through studying the actual supply chains in nine locations around the Northeast region and doing extensive modeling and analysis of secondary data on food systems, we have attempted to understand the extent to which the region can rely on its own food production and can meet the needs of low-income

Disclosure

The research was supported by the U.S. Department of Agriculture National Institute of Food and Agriculture (USDA NIFA) Agriculture and Food Research Initiative (AFRI) grant \#2011-68004-30057: Enhancing Food Security in the Northeast through Regional Foods Systems (EFSNE). 
populations. This issue of JAFSCD presents an initial set of three papers that summarize key insights gathered so far. These papers explore (1) the food system as viewed through an eightproduct market basket, (2) our experience engaging and informing stakeholders, and (3) consumers' perceptions of regional food. Papers to be published in a later issue are likely to cover (4) our educational activities and their impact on students and trainees, (5) the distribution of products in the Northeast food system, and (6) the capacity of the region to produce food.

\section{Keywords}

Interdisciplinary; Multidisciplinary; Regional Food System; Transdisciplinary

\section{Purpose of the Collected Papers}

Systems of all types can be difficult to define, let alone to understand. As the adage about the blind men and the elephant explains, when one only touches a part of a system, one fails to grasp the whole. Likewise, study within disciplines offers deep insights on a single part or dimension of a system, but may fail to place that knowledge in a larger perspective. Multidisciplinary, interdisciplinary, and, most recently, transdisciplinary research have been promoted as strategies for studying systems or solving complex problems that involve cutting across domains.

Without parsing too finely what distinguishes each of these terms, noting a couple of key characteristics is instructive. "Multidisciplinary," "interdisciplinary," and "transdisciplinary" research all involve people from more than one, and often many, disciplines working together on a common project and usually connote different degrees of collaboration (Kajikawa, 2008).

Conducting such research, however, is no easy task. Brandt et al. (2013), for example, identify five challenges to performing transdisciplinary research: (1) coherently framing a problem, issue, or question; (2) integrating methods across disciplines; (3) organizing the research process; (4) meaningfully engaging practitioners; and (5) generating broad, rather than just local, impact. Given such challenges, it is essential to communicate what is learned through large, cross-disciplinary projects, both in terms of the knowledge gained and the process followed.

As members of a large, integrated project with research, education, and outreach elements, we have a unique opportunity to present what an interdisciplinary (or perhaps transdisciplinary) approach can contribute. The Enhancing Food Security in the Northeast (EFSNE) project commenced in 2011 to explore the potential for regional food systems to improve food security in the Northeastern U.S. The audience for our work spans a wide range of individuals, from academics and policymakers to low-income community members. The purpose of this set of papers is to share insights from our experience studying and communicating about regional food systems and food security.

\section{The Enhancing Food Security in the Northeast (EFSNE) Project}

The EFSNE project was conceived in 2010 as a proposal to the U.S. Department of Agriculture (USDA) Agriculture and Food Research Initiative's challenge area on global food security. Twenty investigators from 11 institutions (land grants, private universities, USDA agencies, and nonprofits), led by a core group at Penn State University, put forward the idea for a five-year project to assess whether greater reliance on regionally produced foods can improve food security for lowincome communities, while also benefiting farmers, food supply-chain firms, and others in the food system. USDA awarded funding to the project in 2011, initiating what has become a seven-year collaboration to study regional food security and food systems in the Northeastern U.S. ${ }^{1}$

Two different, but complementary, definitions of food security orient the EFSNE work. Food security describes the extent to which states, regions, or nations are self-reliant in food production, and it also refers to conditions in which all residents, including those living in poverty, obtain a

\footnotetext{
${ }^{1}$ The Northeastern region comprises Connecticut (CT), Delaware (DE), the District of Columbia (DC), Maine (ME), Maryland (MD), Massachusetts (MA), New Hampshire (NH), New Jersey (NJ), New York (NY), Pennsylvania (PA), Rhode Island (RI), Vermont (VT), and West Virginia (WV).
} 
safe and adequate diet. Both definitions are important across time and should be addressed simultaneously. The EFSNE project has focused on a regional scale because it is an appropriate one for addressing rural development, public health, agricultural strategies, and other important issues. Nested within it are local efforts, while the larger scale offers a more ecological focus on population density, environmental conditions, and marketing infrastructure. Our work has been motivated by an interest in agricultural sustainability, a broad concept that encompasses environmental, economic, and quality-of-life concerns, in addition to food, feed, and fiber production (National Research Council, 2010). However, food security has been the focus of the project.

We have taken an interdisciplinary, systems approach to understanding food security. Recognizing that food security issues require insights from multiple disciplines and knowledge-sharing between researchers and community practitioners, we used multiple quantitative and qualitative methods in the project: interviews, surveys, focus groups, secondary data analysis, and modeling, and others. We have attempted to study entire food systems through analysis of primary data collected in communities, stores, and the supply chains that serve them, and of secondary data on the food system available from public and private sources. Primary data were gathered from nine locations across the region, including five urban areas (Baltimore, MD; Charleston, WV; New York, NY; Pittsburgh, PA; Onondaga County, NY; and Syracuse, NY) and three rural areas (Essex County, VT; Madison County, NY; and Southern Delaware [DE]). Secondary data from a wide range of sources were gathered on the region as a whole.

The team includes more than 20 researchers from 12 academic disciplines and has involved dozens of undergraduates, graduate students, postdocs, and community liaisons who played key roles in the project. To make the project tractable, we relied on a robust organizational structure that distributed leadership responsibility through three research teams focused on consumption, distribution, and production; three teams to manage the project's activities in outreach, education, and evaluation; and a seventh team to enhance com- munication among the modelers. Most members of the project served on multiple teams, creating a well-integrated environment that encouraged collaboration and required communication across disciplines. Indeed, the project evolved to become increasingly transdisciplinary as it progressed.

\section{Synopses of the Papers in this Issue}

The papers here explore both how we worked and what we learned, themes that will be addressed further in other planned publications from the project, including papers to be published in a future issue of JAFSCD.

In the first paper, Clancy et al. (2017) synthesize lessons learned about the Northeast food system through the market basket of foods examined in the EFSNE project. Analyses of the eight market basket items serve as a window into food access, availability, and affordability and into regional production, processing, and distribution.

In the second paper, a commentary, Ruhf et al. (2017) present the strategy used to engage and inform stakeholders. Within the EFSNE project, outreach has been viewed as a two-way street between researchers and stakeholders. The paper describes the deliberate approach that was taken to reach a range of audiences through a variety of inperson activities and communication resources.

In the third paper, Palmer et al. (2017) explore how consumers understand the concept of regional food based on focus groups conducted in four locations across the Northeast. Analysis of participant discussions yields insights on how consumers define and value regional food, relative to the more familiar concept of local food.

\section{Conclusions}

The EFSNE project's objectives were to provide evidence, analyses, and knowledge of the accessibility of regionally produced foods in the Northeast and recommendations on what might be changed —and with what possible consequences - going into the future. We believe we have accomplished these objectives in many ways. We hope readers will be inspired to consider their own definitions of "regional" and to take away a sense of the capacity of the Northeast region's farms and food infrastructure to meet regional food needs. 
In addition, we think these papers offer a glimpse of how transdisciplinary inquiry can influence education and the relationship between researchers and stakeholders in integrated research. The EFSNE project started as an interdisciplinary endeavor and became more transdisciplinary as the work progressed; the team was surprised by both unexpected successes and underestimated challenges. We expect that readers will come to their own conclusions about the value of large, interdisciplinary and transdisciplinary research projects, and hope that, on balance, the stories from the EFSNE project leave the reader with a sense of cautious optimism.

\section{References}

Brandt, P., Ernst, A., Gralla, F., Luederitz, C., Lang, D. J., Newig, J., Reinert, F., Abson, D. J., \& von Wehrden, H. (2013). A review of transdisciplinary research in sustainability science. Ecological Economics, 92, 1-15. http://doi.org/10.1016/i.ecolecon.2013.04.008

Clancy, K., Bonanno, A., Canning, P., Cleary, R., Conrad, Z., Fleisher, D., Gomez, M., Griffin, T., Lee, R., Kane, D., Palmer, A., Park, K., Peters, C., \& Tichenor, N. (2017). Using a market basket to explore regional food systems. Journal of Agriculture, Food Systems, and Community Development, 7(4), 163-178. http://dx.doi.org/10.5304/jafscd.2017.074.018

Kajikawa, Y. (2008). Research core and framework of sustainability science. Sustainability Science, 3(2), $215-239$. http://dx.doi.org/10.1007/s11625-008-0053-1

National Research Council. (2010). Toward Sustainable Agricultural Systems in the $21^{\text {st }}$ Century. Washington, D.C.: The National Academies Press. https://doi.org/10.17226/12832

Palmer, A., Santo, R., Berlin, L., Bonanno, A., Clancy, K., Giesecke, C., Hinrichs, C. C., Lee, R., McNab, P., \& Rocker, S. (2017). Between global and local: Exploring regional food systems from the perspectives of four communities in the U.S. Northeast. Journal of Agriculture, Food Systems, and Community Development, 7(4), 187-205. http://dx.doi.org/10.5304/jafscd.2017.074.017

Ruhf, K. Z., Devlin, K., Clancy, K., Berlin, L., \& Palmer, A. (2017). Engaging multiple audiences: Challenges and strategies in complex food systems projects. Journal of Agriculture, Food Systems, and Community Development, 7(4), 179-185. http://dx.doi.org/10.5304/jafscd.2017.074.016 